\title{
Nonsurgical treatment of hemifacial microsomia by therapeutic ultrasound and hybrid functional appliance
}

This article was published in the following Dove Press journal:

Patient Preference and Adherence

25 March 2010

Number of times this article has been viewed

\author{
Tarek El-Bialy' \\ Ali Hasan ${ }^{2}$ \\ Ahmad Janadas ${ }^{3}$ \\ Tarik Albaghdadi ${ }^{4}$ \\ 'Division of Orthodontics, \\ Department of Dentistry, University \\ of Alberta, Edmonton, Alberta, \\ Canada; ${ }^{2}$ Division of Orthodontics, \\ Department of Preventive Dental \\ Sciences, Faculty of Dentistry; \\ ${ }^{3}$ Division of Oral and Maxillofacial \\ Surgery, Department of Oral and \\ Maxillofacial Surgery, Faculty of \\ Dentistry; ${ }^{4}$ Division of Radiology, \\ Faculty of Medicine, King Abdul Aziz \\ University, Jeddah, Saudi Arabia
}

\begin{abstract}
Aim: Conventional treatment of patients with hemifacial microsomia involves orthognathic surgery and/or distraction osteogenesis of the mandible. Previous reports showed that low-intensity pulsed ultrasound (LIPUS) enhances mandibular growth in growing rabbits and monkeys. In monkeys, LIPUS enhanced mandibular growth when combined with functional jaw orthopedic appliances. The purpose of this pilot study was to investigate if LIPUS could enhance mandibular growth in children with hemifacial microsomia.

Methods: Five children (age range 3-11 years) with hemifacial microsomia were treated with hybrid jaw orthopedic functional appliances and treatment of the affected mandibular condyle by LIPUS for 20 minutes per day.

Results: The results showed that after one year of treatment, significant improvement of the underdeveloped side of patients' faces and mandibles was recognized both clinically and radiographically.

Discussion: Although improvement took a longer time than did a surgical approach, optimizing this technique may achieve better results in a shorter treatment time. A randomized controlled clinical trial to investigate the effect of optimized LIPUS application or functional appliances in the treatment of hemifacial microsomia is warranted.
\end{abstract}

Keywords: hemifacial microsomia, LIPUS, non-surgical treatment, children

\section{Introduction}

Hemifacial microsomia (HFM) is a congenital anomaly characterized by an asymmetric facial defect in which the mandible and overlying structures fail to develop normally. HFM is also known by other names, including otomandibular dysostosis; ${ }^{1}$ first and second branchial arch syndrome; ${ }^{2,3}$ oculo-auriculovertebral sequence; ${ }^{4}$ Goldenhar syndrome; 5,6 lateral facial dysplasia $;^{7}$ and craniofacial microsomia. ${ }^{8,9}$ The prevalence of HFM is variously reported to be in the range of 1 in 3000 to 1 in 5600 births. $^{10-13}$ Males have been reported to be more affected than females, ${ }^{14}$ and the right side of the face is affected more often than the left side (three times compared with two). ${ }^{15}$ The exact etiology of HFM is not fully understood. It has been reported from a murine study to be a developmental abnormality mainly due to hemorrhage and rupture of the stapedial artery (a small blood vessel near the ear). ${ }^{14,16}$ However, the results of experiments in mice cannot be extrapolated to humans, and there are no published reports indicating that intrauterine trauma or excessive motion of the mother might cause such a problem in humans. Although different classifications have been reported in the literature, the Pruzansky classification continues to be the HFM classification used most often by clinicians and researchers. ${ }^{17-19}$
Correspondence:Tarek El-Bialy 405I C Dentistry/Pharmacy Centre, University of Alberta, Edmonton, Alberta, Canada, T6G 2N8

Tel +l 780492275 I

Fax +I 7804927105

Email telbialy@ualberta.ca 
Management of HFM depends on the severity of the case as well as the age of the affected patient. Routine management of HFM patients involves the orthodontic use of hybrid functional appliances and/or surgical intervention. ${ }^{20}$ Low-intensity pulsed ultrasound (LIPUS) has been used to promote bone fracture healing in humans, ${ }^{21}$ aid bone maturation during distraction osteogenesis, ${ }^{22}$ modify growth in end plates, ${ }^{23}$ and stimulate mandibular growth in growing rabbits ${ }^{24}$ and monkeys. ${ }^{25}$ However, the outcome of ultrasound treatment varies between species. It has been reported that clinically significant results can be obtained in rabbits using four weeks of LIPUS, ${ }^{24}$ whereas clinically significant outcomes were achieved after four months of LIPUS treatment in monkeys. ${ }^{25}$ The monkey study also showed a synergetic effect of LIPUS and forward bite-jumping appliances, the latter being known in orthodontics as functional appliances. There is a paucity of information about the potential stimulatory effect of LIPUS with or without functional appliance use in the treatment of underdeveloped halves of the mandibles in patients with HFM.

\section{Methods}

Five patients with HFM of variable severity agreed to participate in this pilot study. Patient age and HFM severity is shown in Table 1. The treatment protocol included daily application of LIPUS along with a hybrid forward bitejumping appliance (Figure 1). The patients ranged in age from three to 11 years. LIPUS application was performed
Table I Patient distribution by age, gender and severity of HFMS

\begin{tabular}{llrll}
\hline Patient & Gender & Age & $\begin{array}{l}\text { Pruzansky } \\
\text { classification }\end{array}$ & $\begin{array}{l}\text { Treatment } \\
\text { time (months) }\end{array}$ \\
\hline WAS & Female & II & Grade II & 8 \\
AFN & Male & 7 & Grade I & 12 \\
JA & Male & II & Grade II & 8 \\
SAT & Female & 3 & Grade I & 12 \\
DBS & Female & 4 & Grade II & 12 \\
\hline
\end{tabular}

using the Exogen SFSHAS ${ }^{\circledR}$ (Exogen Inc., New Jersey, USA) healing system (Figure 2). LIPUS application was performed for 20 minutes daily for 8-12 months. Based on clinical outcome, the patients either stopped using this technique or decided to go for regular orthognathic surgery utilizing distraction osteogenesis technique. Lateral and postero-anterior cephalometric radiographs were analyzed ${ }^{26}$ at baseline and after treatment. Landmarks used for lateral and postero-anterior cephalometric analyses are outlined in Table 2 and Figure 3.

\section{Results}

Cephalometric analysis of the pre- and post-treatment radiographs is presented in Table 3. Also, Figure 4 shows postero-anterior cephalometric radiographs before and after treatment for two patients. Some point A-nasionpoint B changes were seen after treatment $(-1.4 \pm 1.9$, see Figure 3), suggesting improvement in patient profiles, especially in mild to moderate cases (except in one patient

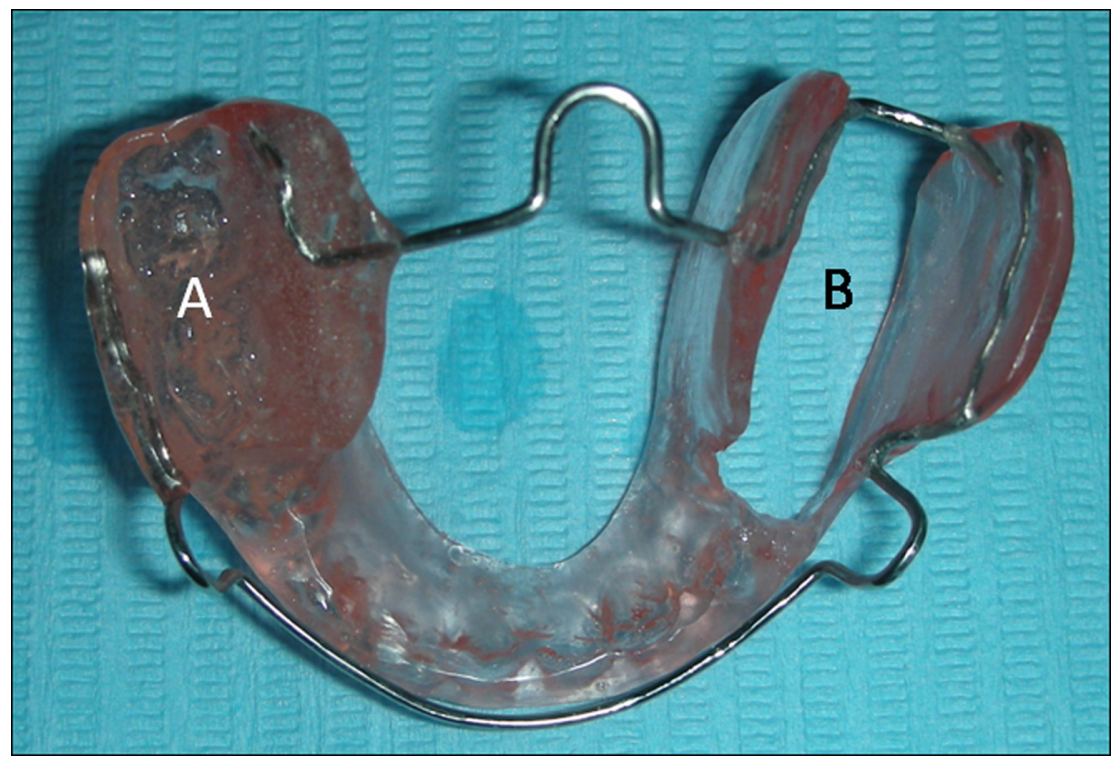

Figure I Hybrid functional bite jumping appliance. A) Occlusal stop on the normal side to prevent the posterior teeth from eruption. B) Occlusal clearance to allow deficient side posterior teeth to erupt. 


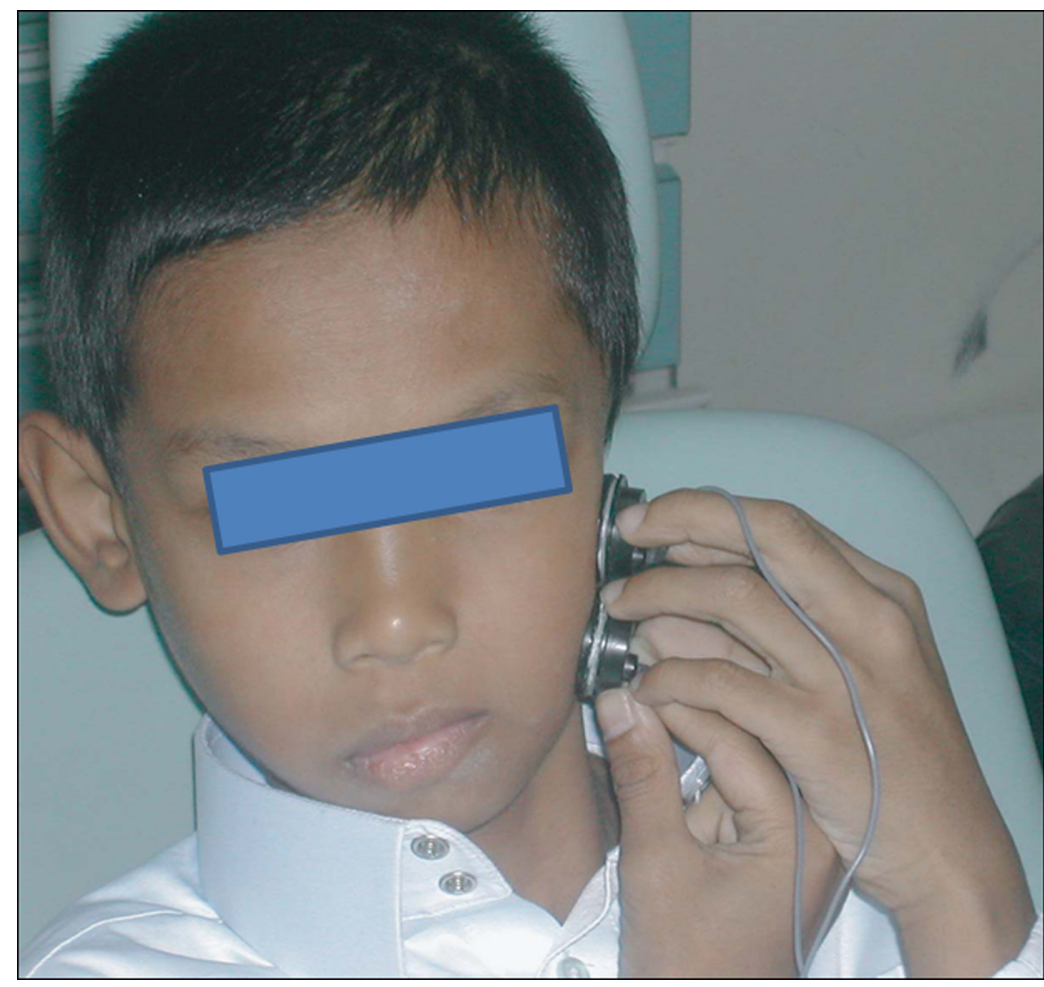

Figure 2 LIPUS device as being applied to the TMJ area of the affected side.

Abbreviations: LIPUS, low-intensity pulsed ultrasound;TMJ, temporomandibular joint.

[WAS] with severe disease [Pruzansky Grade II]). Steepness of the mandibular plane relative to the anterior cranial base (SN-MPd) on the affected side showed more improvement ( $-3.4 \pm 3.4$ [range -1 to -9 ] degrees) than on the unaffected side ( $-3 \pm 2$ [range 0 to -5 ] degrees). However there was no statistically significant difference between the affected and unaffected sides $(P=0.8)$.

There was also a significant increase in mandibular ramus height (Ag-Co d), with an increase on the affected side after treatment $(4 \pm 2.7$ [range 1-8] $\mathrm{mm}, P=0.03)$ that was comparable with the unaffected side (4-2.9 [range $0-8] \mathrm{mm}, P=0.03)$. Also, mandibular vertical displacement (Ag-Z) on the affected side showed an increase after treatment $(6.2 \pm 3.6$ [range 1-11] $\mathrm{mm})$ that was also comparable with the unaffected side $(5.6 \pm 3.4$ [range 1-9] mm). Also, there was a comparable change in the outside displacement of the mandibular angle relative to the maxilla (Ag-J) on both the affected $(1.8 \pm 2.2$ [range $0-5] \mathrm{mm})$ and unaffected sides (2.2 \pm 2.7 [range 0-6] $\mathrm{mm}$ ). Moreover, mandibular body length (Ag-me) on the affected sides showed more increase (2.4 \pm 0.5 [range 2-3] mm, $P=0.0006)$ than on the unaffected sides (1.4 \pm 1.1 [range 0-3], $P=0.05$ ). However, there was no statistically significant difference between the change in the affected and unaffected sides $(P=0.1)$.

\section{Discussion}

It is known that HFM is a progressive disease such that growth of the affected side is always less than that of the normal side. ${ }^{17} \mathrm{~A}$ noninvasive technique that can improve or normalize the growth pattern of the affected side in HFM would be preferable to using conventional surgical techniques. A previous report in a patient with HFM showed that using a hybrid functional appliance only could induce condylar growth. ${ }^{27}$ However, the results achieved with the functional appliance were obtained over a five-year period and the conclusion of that report emphasized that a high degree of patient compliance would be needed to achieve such results over a longer period of time. Based on the previously positive results showing enhanced mandibular growth with LIPUS with or without using bite-jumping appliances in animals over periods of four weeks to four months, ${ }^{24,25}$ it seemed reasonable to evaluate the effectiveness of using LIPUS in patients with HFM, even though enrolling patients into such a study who are well matched for age, gender, and severity of HFM is a challenge.

The data presented here show that use of LIPUS and a bite-jumping appliance normalizes the growth pattern of the affected mandibular side to a greater extent in younger children (3-7 years) than in older ones (11 years) and also in mild to 
Table 2 Cephalometric landmarks used to analyze lateral and cephalometric radiographs

\section{Landmark/measurement \\ Lateral cephalometric landmarks}

Sella

Nasion

A point

B point

Menton (Me)

Lateral cephalometric measurements SNA

SNB

SN-Mandibular plane angle

FMA

Posteroanterior cephalometric landmarks

$\mathrm{Ag}$

Z

J

\section{Condylion (Co)}

Posteroanterior cephalometric measurements

$\mathrm{Ag}-\mathrm{Co}$

$\mathrm{Ag}-\mathrm{Z}$

$\mathrm{Ag}-\mathrm{J}$

Ag-Me

\section{Definition}

Mid point of the sella turcica

Deepest point of the frontonasal suture

Deepest point of the anterior concavity in the upper jaw between anterior nasal spine and alveolar bone and it represents the anterior limit of the maxillary basal bone

Deepest point of the anterior concavity in the lower jaw between anterior nasal spine and alveolar bone and it represents the anterior limit of the maxillary basal bone

Deepest point on the inferior concavity of the mandibular symphysis

The angle between the anterior cranial base and A point. It represents the anteroposterior relationship of the maxillary basal bone to the anterior cranial base.

The angle between the anterior cranial base and B point. It represents the anteroposterior relationship of the mandibular basal bone to the anterior cranial base.

The angle between the anterior cranial base (SN) and the tangent of the inferior surface of the body of the mandible where $d$ indicates deficient side and $\mathrm{n}$ indicates normal side.

The angle between Frankfurt horizontal plane angle (Porion to orbitale) and the tangent of the inferior surface of the body of the mandible where $d$ indicates deficient side and $n$ indicates normal side.

\section{Antigonion notch}

Medial aspect of the zygomatic frontal suture

Jugal process (Deepest point in the concavity between the upper molar alveolar crest and the ascending zygomatic arch)

Most superior aspect of the contour of the mandibular condyle

Linear measurement between $\mathrm{Ag}$ and $\mathrm{Co}$. It indicates mandibular ramal height

It indicates the vertical mandibular distance between the mandibular angle and the zigomaticofrontal suture Linear measurement between $\mathrm{Ag}$ and Jugular point. It represents the in-out distance between mandibular angle and J point

Linear measurement that represents mandibular body length on either $d$ (deficient side) or $n$ (normal side)

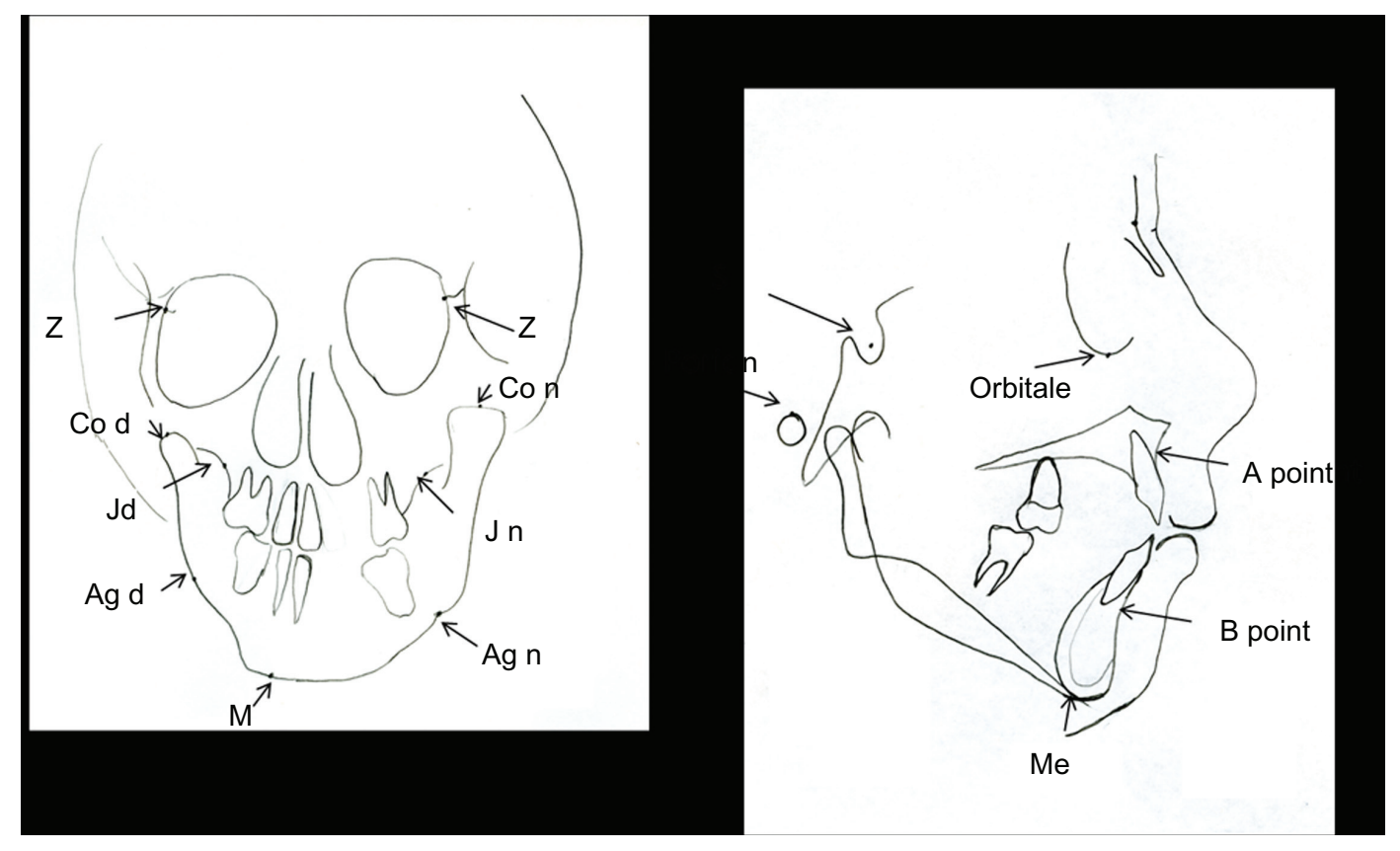

Figure 3 Lateral and postero-anterior cephalometric landmarks used for the analysis. 
Table 3 Cephalometric measurements before and after treatment

\begin{tabular}{|c|c|c|c|c|c|c|c|c|c|}
\hline \multirow[t]{2}{*}{ Measurements } & \multicolumn{5}{|c|}{ Patients } & \multirow{2}{*}{$\begin{array}{l}\text { Average } \\
\text { change }\end{array}$} & \multirow{2}{*}{$\begin{array}{l}\text { Standard } \\
\text { deviation }\end{array}$} & \multirow{2}{*}{$\begin{array}{l}\text { Paired } \\
\text { t-test }\end{array}$} & \multirow{2}{*}{$\begin{array}{l}\text { Unpaired } \\
\text { t-test }\end{array}$} \\
\hline & WAS & AFN & JA & SAT & DBS & & & & \\
\hline SNA (before) & 81 & 71 & 83 & 80 & 78 & & & & \\
\hline SNA (after) & 81 & 72 & 83 & 81 & 79 & & & & \\
\hline SNA difference & 0 & I & 0 & I & 1 & 0.6 & 0.5 & 0.07 & \\
\hline SNB (Before) & 74 & 63 & 77 & 76 & 70 & & & & \\
\hline SNB (after) & 76 & 64 & 80 & 76 & 75 & & & & \\
\hline SNB difference & 2 & I & 3 & 0 & 5 & 2.2 & 1.9 & 0.06 & \\
\hline ANB (before) & 7 & 8 & 5 & 4 & 8 & & & & \\
\hline ANB (after) & 5 & 8 & 3 & 5 & 4 & & & & \\
\hline ANB difference & -2 & 0 & -2 & 1 & -4 & -1.4 & 1.9 & 0.2 & \\
\hline SN-MP d (before) & 48 & 64 & 57 & 50 & 53 & & & & \\
\hline SN-MP d (after) & 46 & 55 & 56 & 46 & 52 & & & & \\
\hline SN-MP d difference & -2 & -9 & -1 & -4 & -1 & -3.4 & 3.6 & 0.08 & \\
\hline SN-MP n (before) & 40 & 55 & 50 & 42 & 39 & & & & \\
\hline SN-MP n (after) & 40 & 50 & 46 & 38 & 37 & & & & \\
\hline SN-MP n difference & 0 & -5 & -4 & -4 & -2 & -3 & 2 & 0.03 & SN/Mp d-n 0.8 \\
\hline FMA d (before) & 36 & 55 & 53 & 43 & 39 & & & & \\
\hline FMA d (after) & 33 & 55 & 49 & 40 & 38 & & & & \\
\hline FMA d difference & -3 & 0 & -4 & -3 & -1 & -2.2 & 1.6 & 0.04 & \\
\hline FMA n (before) & 31 & 45 & 46 & 35 & 25 & & & & \\
\hline FMA n (after) & 31 & 42 & 39 & 32 & 21 & & & & \\
\hline FMA n difference & 0 & -3 & -7 & -3 & -4 & -3.4 & 2.5 & 0.038 & FMA d-n 0.4 \\
\hline Ag-Z d (before) & 79 & 95 & 62 & 65 & 58 & & & & \\
\hline Ag-Z d (after) & 85 & 96 & 73 & 71 & 65 & & & & \\
\hline Ag-Z d difference & 6 & 1 & 11 & 6 & 7 & 6.2 & 3.6 & 0.018 & \\
\hline Ag-Z n (before) & 91 & 85 & 71 & 75 & 67 & & & & \\
\hline Ag-Z n (after) & 99 & 88 & 79 & 76 & 76 & & & & \\
\hline Ag-Z $n$ difference & 8 & 3 & 7 & I & 9 & 5.6 & 3.4 & 0.02 & Ag-Z d-n 0.8 \\
\hline Ag-Co d (before) & 33 & 61 & 42 & 32 & 26 & & & & \\
\hline Ag-Co d (after) & 37 & 62 & 50 & 37 & 28 & & & & \\
\hline Ag-Co d difference & 4 & 1 & 8 & 5 & 2 & 4 & 2.7 & 0.03 & \\
\hline Ag-Co n (before) & 59 & 36 & 50 & 42 & 42 & & & & \\
\hline Ag-Co n (after) & 62 & 44 & 54 & 42 & 47 & & & & \\
\hline Ag-Co $n$ difference & 3 & 8 & 4 & 0 & 5 & 4 & 2.9 & 0.03 & Ag-Co d-n I \\
\hline Ag-J d (before) & 32 & 41 & 29 & 28 & 20 & & & & \\
\hline Ag-J d (after) & 32 & 41 & 30 & 31 & 25 & & & & \\
\hline Ag-J d difference & 0 & 0 & I & 3 & 5 & 1.8 & 2.2 & 0.13 & \\
\hline Ag-J n (before) & 39 & 38 & 26 & 31 & 30 & & & & \\
\hline Ag-J n (after) & 40 & 38 & 32 & 31 & 34 & & & & \\
\hline Ag-J $n$ difference & 1 & 0 & 6 & 0 & 4 & 2.2 & 2.7 & 0.14 & $A g-J d-n 0.8$ \\
\hline Ag-me d (before) & 44 & 47 & 50 & 35 & 35 & & & & \\
\hline Ag-me d (after) & 47 & 49 & 52 & 37 & 38 & & & & \\
\hline Ag-me d difference & 3 & 2 & 2 & 2 & 3 & 2.4 & 0.5 & 0.0006 & \\
\hline Ag-me n (before) & 56 & 37 & 53 & 41 & 39 & & & & \\
\hline Ag-me n (after) & 57 & 39 & 53 & 44 & 40 & & & & \\
\hline Ag-me $n$ difference & I & 2 & 0 & 3 & I & 1.4 & I.I & 0.05 & Ag-me d-n 0.1 \\
\hline
\end{tabular}

Abbreviations: $\mathrm{d}$ (deficient side); $\mathrm{n}$ (normal side); $\mathrm{d}$-n (unpaired t-test between the normal and deficient sides' measurements). 


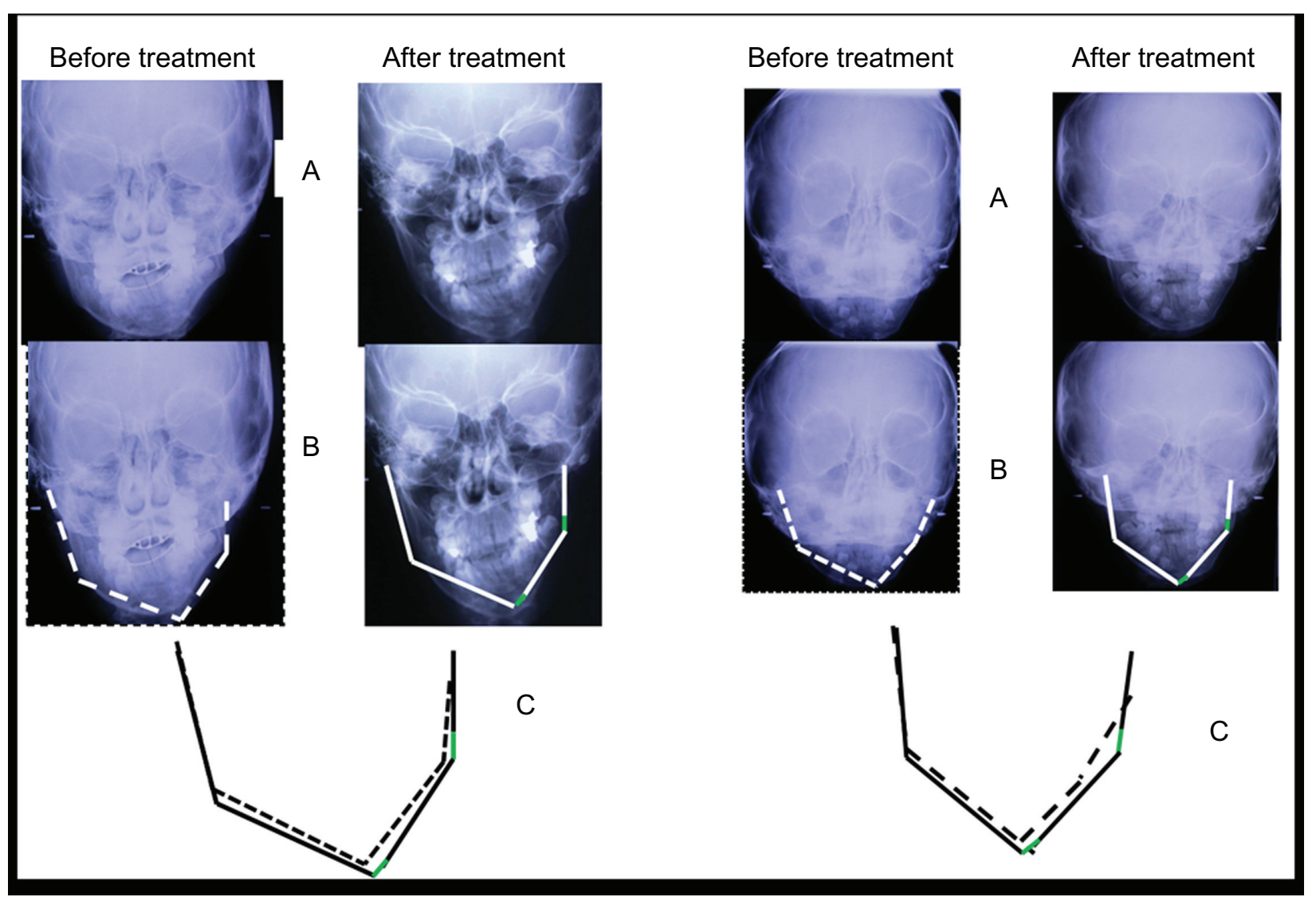

Figure 4 Two patients' postero-anterior cephalometric radiographs A) before and after treatment; B) linear measurements before (black) and after (difference in green) and C) superimposition of before and after linear measurements show the differences in the affected side mandibular ramus and body.

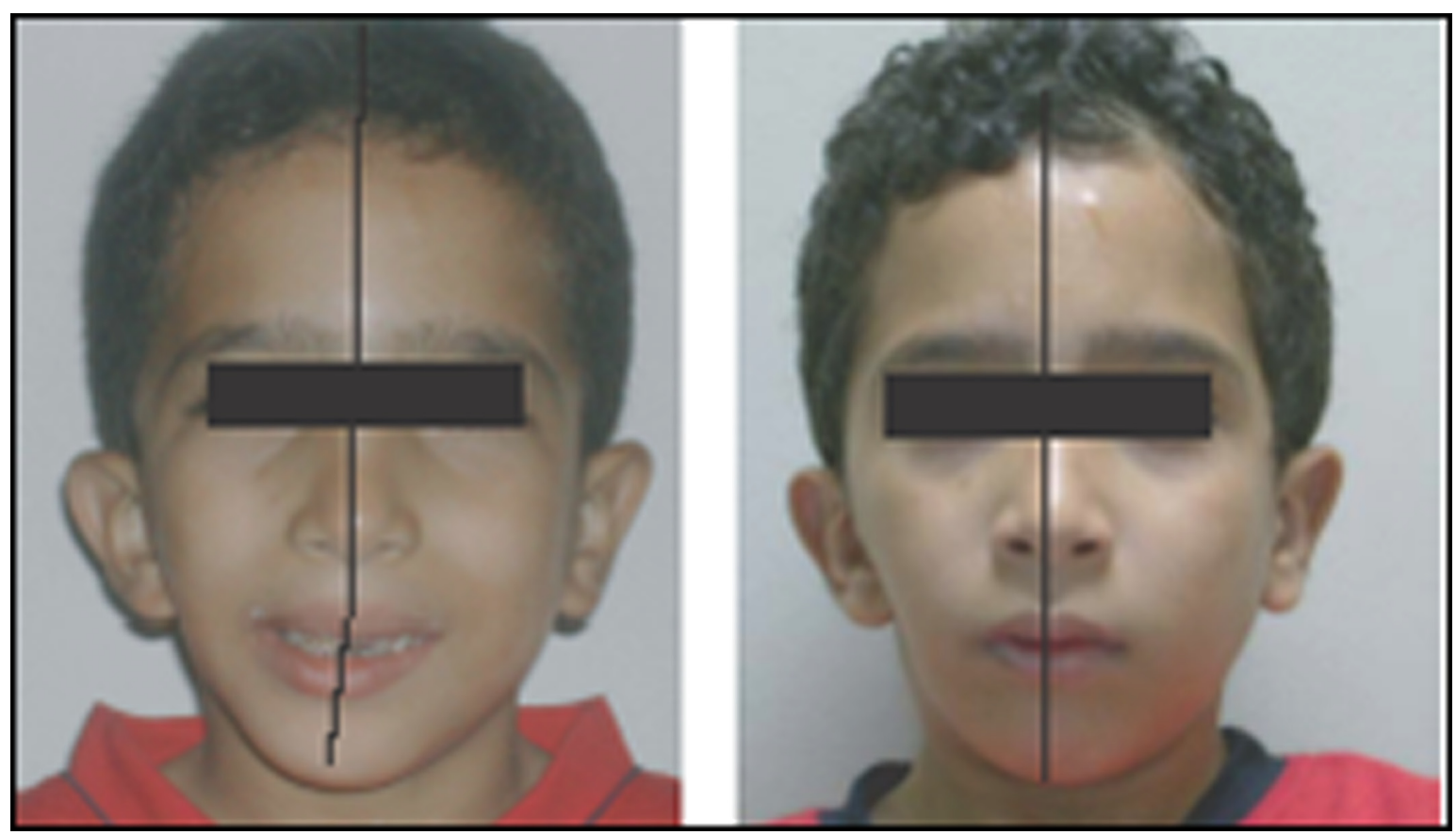

Figure 5 Patient AFN before (left photo) and after (right photo) treatment with LIPUS and hybrid functional appliance for 12 months. 


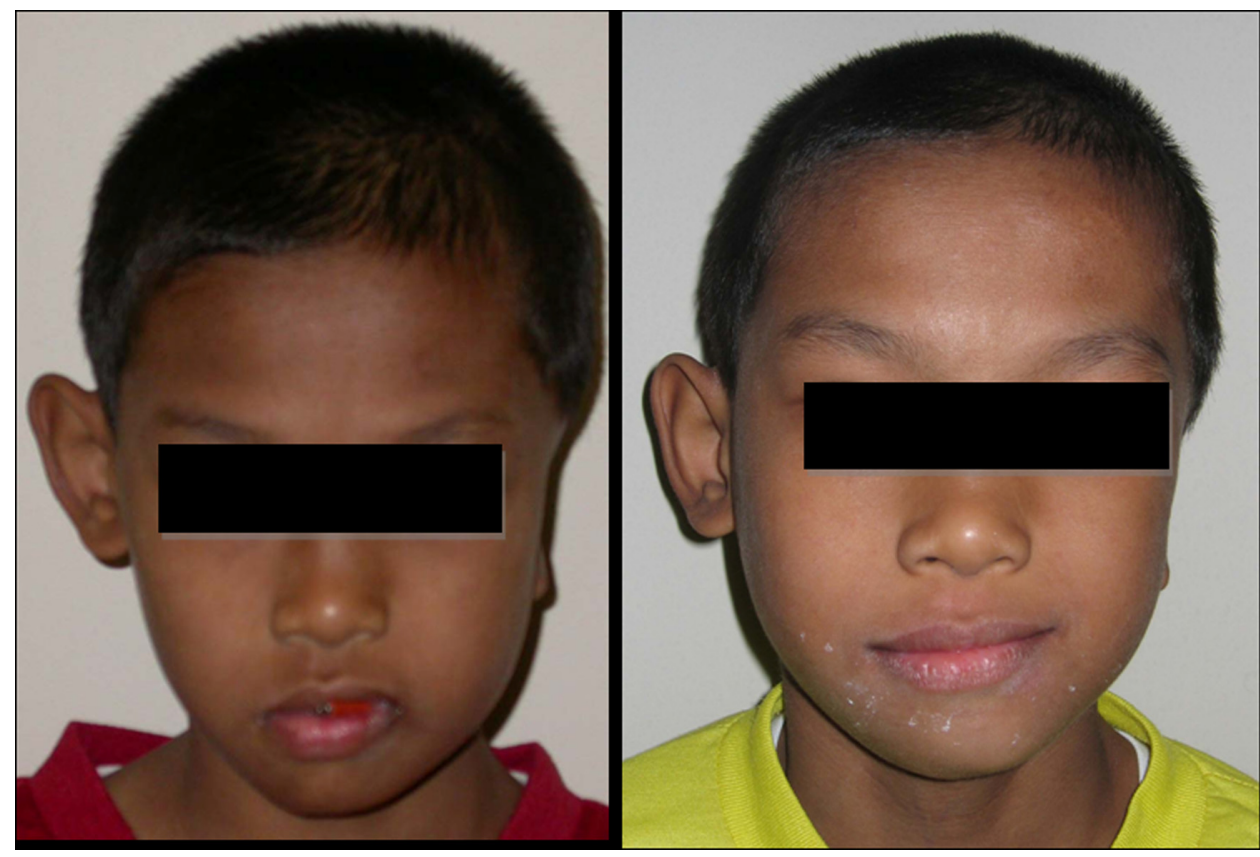

Figure 6 Patient JA before (left photo) and after (right photo) treatment with LIPUS and hybrid functional appliance for 8 months.

moderate cases rather than severe ones. The normalized growth pattern on the affected sides is reflected in the lack of a significant difference in the changes after treatment in linear measurements between the affected and unaffected sides (Table 3). It should also be noted that the improvement achieved with this technique is comparable with that achieved in monkeys. ${ }^{25}$ However, favorable clinical and histologic results were obtained in monkeys after four months of daily treatment, whereas in the present study done in children, improvement was achieved only after almost a year of treatment. This could be attributable to a difference in metabolic responses between animals and humans, or to the fact that the treated mandibles were normal in the monkeys but were congenitally defective in our HFM children

The relatively long time taken to achieve results using LIPUS and a hybrid appliance in comparison with a surgical option could be a limitation of this technique. On the other hand, although this treatment seems relatively lengthy compared with the surgical option, it is comparatively short compared with use of the hybrid appliance alone (five years). ${ }^{27}$ However, it is noteworthy that surgical interventions for HFM also have limitations which have been well documented in the literature. The similar changes seen on the treated and untreated sides suggest that combined treatment of LIPUS and a bite-jumping appliance might help to normalize growth of the affected side of the mandible in HFM patients. The results of out study are in agreement with those of Kaplan, 1989. ${ }^{27}$ However, ours were achieved in one year, on average, compared with the five-year treatment period reported by Kaplan. This may be due to the fact that Kaplan did not use LIPUS and also the patients in Kaplan's study was older than most of the patients in our study.

The main limitations of this study are its small sample size and lack of homogeneity in patient age and disease severity. However, given the relative rarity of HFM, it would be very difficult to identify sufficient HFM patients of comparable disease severity, gender, and age to be able to undertake a placebo-controlled study in a timely fashion. Another limitation of this study is that it is highly likely that such mere differences could be explained by very minor changes in angle between a face and x-ray, however larger scale studies are needed to validate the present results. Moreover, the long-term stability of our results needs to be monitored in the future. Given the long time taken to achieve our results, future research may be directed to evaluation of additional treatment modalities that might help shorten the treatment time. Nevertheless, despite the above-mentioned limitations, our findings suggest that the LIPUS and hybrid appliance technique could be indicated in patients with less severe HFM, ie, Pruzansky Grade I.

\section{Conclusion}

Within the limitations of this small study population, we conclude that daily application of LIPUS and hybrid bite-jumping appliances may be helpful in enhancing mandibular growth on the affected side in HFM patients, particularly Pruzansky Class II cases. The best results were achieved in younger patients and in those with mild to moderate disease. 


\section{Acknowledgements}

The authors would like to thank Exogen Inc., NJ, USA for their generous support of this research.

\section{Disclosure}

The authors report no conflicts of interest in this work.

\section{References}

1. Francois JJ, Haustrate L. Anomalies colobomateuses du globe oculaire et syndrome du premier arc. Ann Ocul. 1954;187:340-368.

2. Stark RB, Saunders DE. The first branchial syndrome. The oralmandibular-auricular syndrome. Plast Reconstr Surg Transplant Bull. 1962;29:229-239.

3. Grabb WC. The first and second branchial arch syndrome. Plast Reconstr Surg. 1965;36(5):485-508.

4. Gorline RJ, Jue KL, Jacobsen U, Goldschmidt E. Oculoauriculovertebral dysplasia. J Pediatr. 1963;63:991-999.

5. Goldenhar M. Association malformatives de l'oeil et de l'oreille, en particulier le syndrome dermoide epibulbaire-appendices auriculaires-fistula auris congenita et ses relations avec la dysotose mandibulo-faciale. J Genet Hum. 1952;1:243-282.

6. Gorlin RJ, Pindborg JJ, Cohen MM Jr. Syndromes of the Head and Neck. 2nd ed. New York, NY: McGraw-Hill; 1976:546.

7. Ross RB. Lateral facial dysplasia (first and second branchial arch syndrome; hemifacial microsomia). Birth Defects Orig Artic Ser. 1975;11(7):51-59.

8. Converse JM, Coccardo PJ, Becker MH, Wood-Smith D. Clinical aspects of craniofacial microsomia. In: Converse JM, McCarthy JG, Wood-Smith D, editors. Symposium on Diagnosis and Treatment of Craniofacial Anomalies. St. Louis, MO: C.V. Mosby; 1979:461.

9. Horgan JE, Padwa BL, LaBrie RA, Mulliken JB. OMENS-Plus: Analysis of craniofacial and extracraniofacial anomalies in hemifacial microsomia. Cleft Palate Craniofac J. 1995;32(5):405-412.

10. Cohen MM Jr. Perspectives on craniofacial asymmetry. I. The biology of asymmetry. Int J Oral Maxillofac Surg. 1995;24(1 Pt 1):2-7.

11. Cohen MM Jr. Perspectives on craniofacial asymmetry. II. Asymmetric embryopathies. Int J Oral Maxillofac Surg. 1995;24(1 Pt 1):8-12.

12. Cohen MM Jr. Perspectives on craniofacial asymmetry. III. Common and/or well-known causes of asymmetry. Int J Oral Maxillofac Surg. 1995;24(2):127-133.
13. Cohen MM Jr. Perspectives on craniofacial asymmetry. IV. Hemi-asymmetries. Int J Oral Maxillofac Surg. 1995;24(2):134-141.

14. Cousley RR, Wilson DJ. Hemifacial microsomia: developmental consequence of perturbation of the auriculofacial cartilage model. Am J Med Genet. 1992;42:461-466.

15. Wang RR, Andres CJ. Hemifacial microsomia and treatment options for auricular replacement: Review of the literature. J Prosthet Dent. 1999;82(2):197-204

16. Robinson LK, Hoyme HE, Edwards DK, Jones KL. Vascular pathogenesis of unilateral craniofacial defects. J Pediatr. 1987;111(2):236-239.

17. Pruzansky S. Not all dwarfed mandibles are alike. Birth Defects Orig Artic Ser. 1969;5:120-129.

18. Swanson LT, Murray JE. Asymmetries of the lower part of the face. In: Whitaker LA. Randall P, editors. Symposium on Reconstruction of Jaw Deformities. St. Louis, MO: C.V. Mosby; 1978:171.

19. Kaban LB, Mulliken JB, Murray JE. Three-dimensional approach to analysis and treatment of hemifacial microsomia. Cleft Palate J. 1981;18(2):90-99.

20. Moulin-Romsée C, Verdonck A, Schoenaers J, Carels C. Treatment of hemifacial microsomia in a growing child: The importance of co-operation between the orthodontist and the maxillofacial surgeon. J Orthod. 2004;31(3):190-200.

21. Heckman JD, Ryaby JP, McCabe J, Frey JJ, Kilcoyne RF. Acceleration of tibial fracture-healing by noninvasive, low-intensity pulsed ultrasound. J Bone Joint Surg Am. 1994;76(1):26-34.

22. El-Bialy T, Royston TJ, Magin RL, Evans CA, Zaki Ael-M, Frizzell LA. The effect of pulsed ultrasound on mandibular distraction. Ann Biomed Eng. 2002;30(10):1251-1261.

23. Abramovich A. Effect of ultrasound on the tibia of the young rat. J Dent Res. 1970;49(5):1182.

24. El-Bialy T, El-Shamy I, Graber TM. Growth modification of the rabbit mandible using therapeutic ultrasound: Is it possible to enhance functional appliance results? Angle Orthod. 2003;73(6):631-639.

25. El-Bialy T, Hassan A, Albaghdadi T, Fouad HA, Maimani AR. Growth modification of the mandible using ultrasound in baboons: A preliminary report. Am J Orthod Dentofacial Orthop. 2006;130(10): 435.e7-e14.

26. Grummons DC, Kappeyne van de Coppello MA. A frontal asymmetry analysis. J Clin Orthod. 1987;21(7):448-465.

27. Kaplan RG. Induced condylar growth in a patient with hemifacial microsomia. Angle Orthod. 1989;59(2):85-90.
Open Access Journal of Clinical Trials

\section{Publish your work in this journal}

The Open Access Journal of Clinical Trials is an international, peerreviewed, open access journal publishing original research, reports, editorials, reviews and commentaries on all aspects of clinical trial design, management, legal, ethical and regulatory issues, case record form design, data collection, quality assurance and data auditing
Dovepress

methodologies. The manuscript management system is completely online and includes a very quick and fair peer-review system, which is all easy to use. Visit http://www.dovepress.com/testimonials.php to read real quotes from published authors. 